\title{
The Importance of Immunohistochemical Staining with DNAJB9 for the Diagnosis of Fibrillar Glomerulonephritis
}

\author{
David Campos Wanderley ${ }^{1,2 *}$ and Stanley de Almeida Araújo ${ }^{1,2}$ \\ ${ }^{1}$ Institute of Nephropathology, Belo Horizonte, Minas Gerais, Brazil \\ ${ }^{2}$ Electronic Microscopy Center, Federal University of Minas Gerais, Belo Horizonte, Minas Gerais, Brazil
}

Submission: April 20, 2020; Published: April 23, 2020

*Corresponding author: David Campos Wanderley. Avenida Bernardo Monteiro, 971. CEP: 30.150-283. Belo Horizonte, Minas Gerais, Brasil

\begin{abstract}
Fibrillary Glomerulonephritis (FGN) is a rare glomerulopathy, corresponding to less than $1 \%$ of all renal biopsies performed. The pathogenesis mechanisms of FGN are still not completely understood and most cases are considered idiopathic. The clinical presentation is characterized by proteinuria, hematuria, arterial hypertension and renal failure. The evaluation of FGN is a diagnostic challenge in the practice of the pathologist, because there are no morphological characteristics with highly specific or pathognomonic lesion. The use of a sensitive and specific biomarker can make an important contribution to renal pathology and the differential diagnosis of diseases with fibrillar deposits. In this contexto, DNAJB9 can be investigated by immunohistochemical technique and is useful for the diagnostic definition of FGN.
\end{abstract}

Keywords: DNAJB9, Biomarker, Immunohistochemistry, Kidney, Fibrillary GN

Abbreviations: FGN: Fibrillary Glomerulonephritis; LM: light microscopy; IF: immunofluorescence; EM: electron microscopy

\section{Introduction}

\section{What is Fibrillary Glomerulonephritis?}

Fibrillary Glomerulonephritis (FGN) is a rare glomerulopathy, corresponding to less than $1 \%$ of all renal biopsies performed [1]. This entity was first described by Rosenmann and Eliakim in 1977, who reported a patient with nephrotic syndrome who identified a glomerular deposition of amorphous material, which resembled amyloid by light microscopy, but their fibrils shorter than amyloid fibrils in ultrastructural analysis [2]. However, it was only in 1983 that FGN was defined as a distinct glomerular disease [3]. The pathogenesis mechanisms of FGN are still not completely understood and most cases are considered idiopathic [1,4-7]. Approximately one third of the cases, an etiological association is found with malignant neoplasms, dysproteinemia, hepatitis $\mathrm{C}$ and autoimmune diseases $[7,8]$. The clinical presentation is characterized by proteinuria (100\%), hematuria $(\sim 50 \%)$, systemic arterial hypertension $(\sim 70 \%)$ and renal failure [5-7]. Renal survival is poor, with almost $50 \%$ progression to end-stage renal disease within 4 years; however, with good patient survival, being $80 \%$ at 4 years of follow-up [7]. In addition, because there is no effective therapy, a recurrence rate after a kidney allografts variable between 35-50\% [9].

\section{How is a Fibrillary Glomerulonephritis Diagnosed?}

Until recently, the diagnosis of FGN was only possible performing light microscopy (LM), immunofluorescence (IF) and electron microscopy (EM). The EM evidence accumulation od fibrils randomly oriented, straight and nonbranching, with measurements between 10 and $30 \mathrm{~nm}$ in thickness. The is proeminente in mesangium and/or along the glomerular basement membranes $[1,5,7,10]$. IF, in most cases, shows smudgy glomerular staining for IgG, C3 and light chains (kappa and lambda). The IgG4 subtype is the most prevalent, presenting restriction in most cases (80\%); moreover, light chains usually exhibit the same intensity of IF stain $[1,5,6,11,12]$. The LM can exhibit several morphological patterns, but in most cases it shows mesangial proliferation with or without duplication of the glomerular basement membranes (membranoproliferative glomerulonaphritis), with crescentic lesions identified in approximately $25 \%$ of cases $[1,5,6,7,13]$.

Congo red research is important to distinguish FGN from amyloidosis. Deposits in FGN are negative for Congo red, with no birefringence on the green apple under polarized light in the vast majority of cases. However, although infrequent, there is a study that shows Congo red positivity in some patients with FGN [14]. 
The evaluation of FGN is a diagnostic challenge in the practice of the pathologist, because the main diagnostic methods (LM, IF, ME) have limitations. There are no morphological characteristics with highly specific or pathognomonic lesion. Added to this is the fact that such characteristics can also be seen in several other glomerulopathies, such as: Amyloidosis, IgA Nephropathy, Diabetic Glomerulopathy, Immunotactoid Glomerulopathy, Fibronectin Glomerulopathy, Collagen-fibrotic Glomerulopathy, among other deposit glomerulopathies. In addition, access to EM is costly and restricted to a minority of cases, especially in developing countries. Thus, it is clear that FGN is an underdiagnosed disease and that the use of a sensitive and specific biomarker can make an important contribution to renal pathology and the differential diagnosis of diseases with fibrillar deposits. In this context, a new proteomic biomarker, DNAJB9, has been discovered, which can be investigated by immunohistochemical technique and is useful for the diagnostic definition of FGN.

\section{What is DNAJB9 and what is its importance in this context?}

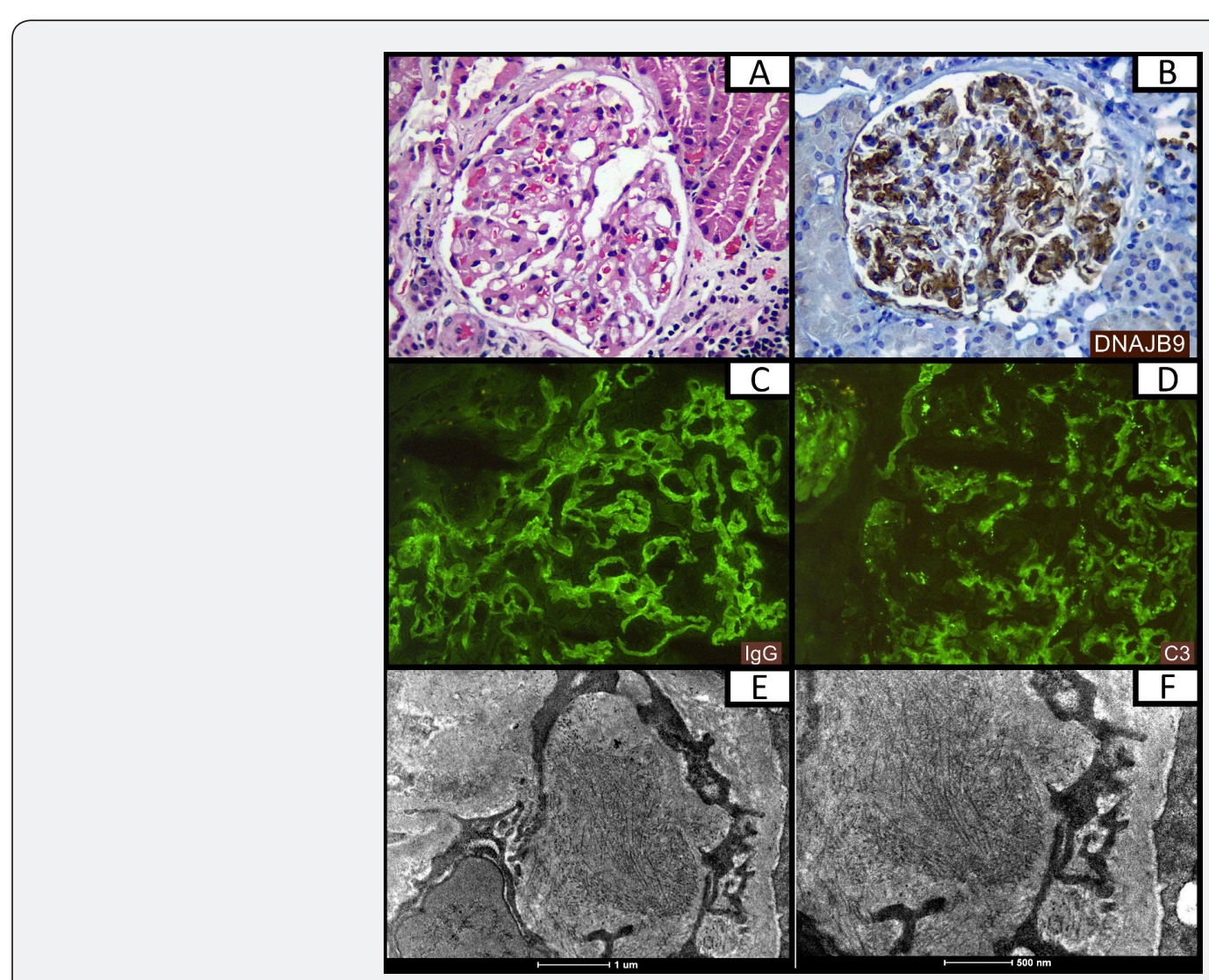

A - Glomerular mesangial expansion (hematoxylin and eosin, x400); B - Immunohistochemistry (DNAJB9) shows strong glomerular staining (x400); C - Immunofluorescence microscopy shows smudgy glomerular staining for $\lg G(x 400)$. D - Immunofluorescence microscopy shows smudgy glomerular staining for C3 (x400). E and F - Electron micrographs exhibit fibrillar deposits composed of randomly oriented, straight, nonbranching fibrils.

Figure 1: Shows the morphological characteristics of a case of FGN by the techniques of LM, IF and EM.

DNAJB9 is a protein that contains 223 -amino acids and is a member of the DNAJ family. DNAJ proteins participate of several fundamental roles, such as regulating ATPases activity, stressing the endoplasmic reticulum, inflammatory mediators actions, differentiating B lymphocytes and producing antibodies, in addition they have protective function against cell death and protects hematopoietic stems cells during stress [15-21]. In the mass spectrometry study, this protein deposition was identified in the glomeruli of all patients diagnosed with FGN and this accumulation was not found in others glomerulopathies $[4,22,23]$. When deposited in the FGN, curiously, no structural protein change was identified [22]. The presence of DNAJB9 can be assessed by immunohistochemistry, which is available in some laboratories specialized in kidney pathology. The first studies with this marker have shown high sensitivity (98-100\%) and specificity (99-100\%) in the diagnosis of FGN $[4,22,23]$. 


\section{Conclusion}

The research of the DNAJB9 protein by immunohistochemical technique has shown high accuracy for the diagnosis of FGN, enabling the diagnostic differentiation with several other glomerulopathies, especially those that exhibit fibrillar deposits. Its discovery and applicability is promising and will allow greater diagnostic precision, avoiding errors and underdiagnosis of FGN.

\section{Conflict of Interest}

The authors declare that they have no conflict of interest

\section{References}

1. Rosenstock JL, Markowitz GS, Valeri AM, Sacchi G (2003) Appel GB, D'Agati VD: Fibrillary and immunotactoid glomerulonephritis: Distinct entities with different clinical and pathologic features. Kidney Int 63: 1450-1461.

2. Rosenmann E, Eliakim M (1983) Nephrotic syndrome associated with amyloid-like glomerular deposits. Nephron 18: 301-308.

3. Duffy JL, Khurana E, Susin M (1977) Fibrillary renal deposits and nephritis. Am J Pathol 113: 279-290.

4. Dasari, Surendra (2018) DnaJ heat shock protein family B member 9 is a novel biomarker for fibrillary GN. Journal of the American Society of Nephrology 29(1): 51-56.

5. Fogo A, Qureshi N, Horn RG (1993) Morphologic and clinical features of fibrillary glomerulonephritis versus immunotactoid glomerulopathy. Am J Kidney Dis 22: 367-377.

6. Iskandar SS, Falk RJ, Jennette JC (1992) Clinical and pathologic features of fibrillary glomerulonephritis. Kidney Int 42: 1401-1407.

7. Nasr SH, Valeri AM, Cornell LD, Fidler ME, Sethi S, et al., (2011) Fibrillary glomerulonephritis: A report of 66 cases from a single institution. Clin J Am Soc Nephrol 6: 775-784.

8. Markowitz GS, Cheng JT, Colvin RB, Trebbin WM, D'Agati VD (1998) Hepatitis C viral infection is associated with fibrillary glomerulonephritis and immunotactoid glomerulopathy. J Am Soc Nephrol 9: 2244-2252.

9. Czarnecki, Peter G (2009) Long-term outcome of kidney transplantation in patients with fibrillary glomerulonephritis or monoclonal gammopathy with fibrillary deposits. Kidney international 75(4): 420-427.
10. Bridoux F, Hugue V, Coldefy O (2002) Fibrillary glomerulonephritis and immunotactoid (microtubular) glomerulopathy are associated with distinct immunologic features. Kidney Int. 62: 1764-1775.

11. Pronovost PH, Brady HR, Gunning ME, Espinoza O, Rennke HG (1996) Clinical features, predictors of disease progression and results of renal transplantation in fibrillary/immunotactoid glomerulopathy. Nephrol Dial Transplant 11: 837-842.

12. Alpers CE, Kowalewska J (2008) Fibrillary glomerulonephritis and immunotactoid glomerulopathy. J Am Soc Nephrol 19: 34-37.

13. Guerra G, Narayan G, Rennke HG, Jaber BL (2003) Crescentic fibrillary glomerulonephritis associated with hepatitis $\mathrm{C}$ viral infection. Clin Nephrol 60: 364-368.

14. Alexander, Mariam P (2018) Congophilic fibrillary glomerulonephritis: a case series. American Journal of Kidney Diseases 72(3): 325-336.

15. Fritz JM, Dong M, Apsley KS, Martin EP, Na CL, et al., (2014) Deficiency of the BiP cochaperone ERdj4 causes constitutive endoplasmic reticulum stress and metabolic defects. Mol Biol Cell 25: 431-440,

16. van Galen P, Kreso A, Mbong N, Kent DG, Fitzmaurice T,et al., (2014) The unfolded protein response governs integrity of the haematopoietic stem-cell pool during stress. Nature 510: 268-272.

17. Behnke J, Mann MJ, Scruggs FL, Feige MJ, Hendershot LM (2016) Members of the Hsp70 family recognize distinct types of sequences to execute ER quality control. Mol Cell 63: 739-752.

18. Wang J, Lee J, Liem D, Ping P (2017) HSPA5 Gene encoding Hsp70 chaperone BiP in the endoplasmic reticulum. Gene 618: 14-23.

19. Tsaryk R, Bartholomä NM, Simiantonaki N, Anspach L, Peters K, et al., (2015) Endoplasmic reticulum-resident chaperones modulate the inflammatory and angiogenic responses of endothelial cells. $\mathrm{Br} \mathrm{J}$ Dermatol 173: 416-427.

20. Kurisu J, Honma A, Miyajima H, Kondo S, Okumura M et al., (2003) MDG1/ERdj4, an ER-resident DnaJ family member, suppresses cell death induced by ER stress. Genes Cells 8: 189-202.

21. Lee HJ, Kim JM, Kim KH, Heo JI, Kwak SJ, et al., (2015) Genotoxic stress/ p53-induced DNAJB9 inhibits the pro-apoptotic function of p53. Cell Death Differ 22: 86-95.

22. Nasr, Samih H (2018) DNAJB9 is a specific immunohistochemical marker for fibrillary glomerulonephritis. Kidney international reports 3(1): 56-64.

23. Andeen, Nicole K (2018) DnaJ homolog subfamily B member 9 is a putative autoantigen in fibrillary GN. Journal of the American Society of Nephrology 29(1): 231-239.

\section{Your next submission with Juniper Publishers will reach you the below assets}

- Quality Editorial service

- Swift Peer Review

- Reprints availability

- E-prints Service

- Manuscript Podcast for convenient understanding

- Global attainment for your research

- Manuscript accessibility in different formats

( Pdf, E-pub, Full Text, Audio)

- Unceasing customer service

Track the below URL for one-step submission https://juniperpublishers.com/online-submission.php 